\section{(Re)aproximando os pragmatismos da análise das políticas públicas. Experimentação e investigação pública em um cenário de crise democrática}

Carolina Andion (https://orcid.org/0000-0003-4723-3437), Curso de Administração Pública e Programa de Pós-Graduação em Administração, Universidade do Estado de Santa Catarina (Udesc), Florianópolis, SC, Brasil'.

Thiago Magalhães (https://orcid.org/0000-0002-6595-6519), Núcleo de Inovações Sociais na Esfera Pública no Centro de Ciências da Administração e Socioeconômicas, Universidade do Estado de Santa Catarina (Udesc), Florianópolis, SC, Brasill".

Resumo: Este ensaio teórico explora as contribuições da lente pragmatista para a análise da governança das políticas públicas em um cenário de crise das democracias. Para tanto, inicia-se abordando o debate recente no campo da administração pública sobre governança e a análise das políticas públicas, evidenciando que esse remete a uma dupla dicotomia: entre modos de governar e de reformar o Estado e de formas de analisar as políticas públicas e seus efeitos. A partir das lacunas evidenciadas nesse debate, adentramos a discussão sobre as noções de experimentalismo democrático e de investigação pública e aprofundamos como tais noções podem ser inspiradoras para olhar de outra forma o "fazer política" cotidiano, especialmente ao considerar os desafios da ação pública na atualidade, diante dos problemas públicos cada vez mais complexos em uma realidade de crise e retrocesso democrático em vários países e, sobretudo, no Brasil.

Palavras-chave: Administração pública. Governança pública. Análise de políticas públicas. Experimentalimso democrático. Investigação pública. Pragmatismo.

(Re)approaching the pragmatisms of public policy analysis. Experimentation and public inquiry in a scenario of democratic crises

Abstract: This theoretical essay explores the contributions of the pragmatist lens to the analysis of public policy governance in a scenario of crisis in democracies. Therefore, it begins by exploring the recent debate in the field of public administration on governance and the analysis of public policies, showing that this leads to a double dichotomy: between ways of governing and reforming the State and ways of analyzing public policies and its effects. From the gaps evidenced in this debate, we entered the discussion on the notions of democratic experimentalism and public inquiry arguing how such notions can be inspiring to look at everyday "policy making" in a dif-
Recebido: 14.04 .21 Aprovado: 17.06 .21

I. Carolina Andion é professora do curso de Administração Pública e do Programa de PósGraduação em Administração da Udesc. <andion.esag@gmail. com>.

II. Thiago Magalhães é membro do Núcleo de Inovações Sociais na Esfera Pública no Centro de Ciências da Administração e Socioeconômicas da Udesc.

<magalhaesgthiago@ gmail.com>. 
ferent way, especially considering the challenges imposed to the public action faced with public problems increasingly complex in a reality of crisis and democratic setback in several countries and, above all, in Brazil.

Keywords: Public Administration. Public governance. Analysis of public policies. Democratic experimentalism. Public inquiry. Pragmatism.

\section{Introdução}

\footnotetext{
egundo dados do relatório Índice da Democracia, do The Economist Intelli$\bigcup$ gence Unit (EIU, 2020), a pontuação média global dos países avaliados caiu de 5,48, em 2018, para 5,44, em 2019 (numa escala de 0 a 10), atingindo a pior pontuação desde que o índice foi produzido, em 2006. Isso foi impulsionado sobretudo pela forte regressão democrática nos países da América Latina, que tiveram o pior desempenho do ano entre todas as regiões do mundo.
}

Essa tendência não se expressa apenas nos índices estatísticos. Diversos são os autores, de várias disciplinas das ciências sociais, que discutem a crise das democracias liberais na atualidade, tanto no Norte como no Sul global. Tais autores utilizam noções semelhantes para qualificar a situação atual vivenciada em diversos países como: crise e ruptura da democracia (Offe, 1996; Bauman, 2000; Santos \& Avritzer, 2003; Santos, 2012; Castells, 2018); esvaziamento da democracia (Dalla Corte \& Dalla Corte, 2018); declínio da democracia e retrocesso democrático (Fukuyama, 2015; Levistsky \& Way, 2015; Levistsky \& Zibllat, 2019; Monedero, 2019). Os autores citados, apesar de apresentarem diferentes compreensões sobre o fenômeno, denunciam que as coisas não vão bem e nos convidam a refletir sobre novas possibilidades, para (re)significar e fortalecer as democracias e a administração pública e a sua governança diante desse cenário.

Ao destacar as múltiplas crises da atualidade, Manuel Castells (2018: 8) sinaliza para a ruptura da relação entre governantes e governados, produzindo a "total decomposição do sistema político, inclusive no Brasil". Tal colapso da democracia liberal, enquanto modelo político de representação e governança, abre espaço, segundo o autor, ao pós-liberalismo, que se caracteriza pela emergência de partidos nacionalistas, xenofóbicos e críticos à política. O autor constata que a crise das democracias tem uma dimensão global, apesar de suas especificidades locais e se configura como um "colapso gradual de um modelo de representação" (Castells, 2018: 10).

Já Steven Levistsky e Daniel Zibllat (2019: 8), a partir de uma análise internacional, discutem o processo de transição para os regimes autocráticos. Ressaltam que as 
democracias, de forma geral, correm riscos, e salientam que "o trágico paradoxo da rota eleitoral para o autoritarismo é que os assassinos da democracia usam as próprias instituições da democracia - gradualmente, sutilmente e até legalmente para matá-la". Para os autores, é nos momentos de crise, como o que vivenciamos atualmente, que as sementes do autoritarismo são cultivadas, a partir de algumas práticas comuns como:

i. a rejeição, em palavras ou ação, das regras democráticas do jogo;

ii. a negação da legitimidade dos oponentes políticos;

iii. a tolerância ou incentivo à violência; e,

vi. a disposição de reduzir as liberdades civis dos oponentes, incluindo a mídia.

No âmbito da administração pública - foco deste artigo -, o debate sobre essa crise mais ampla evidencia que os fatores que podem (re)significar as democracias vão muito além do estabelecimento de procedimentos formais democráticos, como as eleições regulares, livres e justas. Osvaldo lazzetta (2013), por exemplo, argumenta que a lógica da qualidade democrática transcende em muito os elementos procedimentais (pois eles são insuficientes), necessitando reavaliar seu conteúdo (direitos) e seus resultados (atingidos a partir das políticas públicas). Já Francis Fukuyama (2015) discute que a legitimidade de muitas democracias pelo mundo depende tanto do aprofundamento de suas instituições, quanto de sua capacidade de oferecer uma governança de alta qualidade.

Em diálogo com autores pragmatistas contemporâneos, os quais se inspiram no trabalho percussor de John Dewey, nossa tese neste ensaio teórico é a de que os modelos clássicos de estudo da governança e das políticas públicas são insuficientes para compreender e agir diante dos problemas públicos robustos enfrentados nesse cenário de democracias em crise. Isso porque tais leituras se limitam por assumir uma posição normativa, tendendo a olhar para o Estado, os problemas públicos, para a administração pública e para a governança das políticas públicas, a partir de lógicas prescritivas, compreendendo-as a priori, o que limita seus potenciais para pensar e agir sobre estes, tanto em termos de efetividade, quanto de legitimidade.

Portanto, exploramos aqui a contribuição "dos pragmatismos" ${ }^{1}$ para a consecução de análises mais realistas, que permitam compreender mais de perto a (re) configuração da administração pública e da governança das políticas públicas na
1. Utilizamos aqui "pragmatismos" no plural por considerar que a influência do pensamento pragmatista nas ciências sociais é ampla e diversa e se configura por uma pluralidade de abordagens inspiradas ou não diretamente do pragmatismo clássico. Neste artigo, mais especificamente, estamos interessados em explorar mais diretamente as vias abertas pelo pensamento de John Dewey e por outros autores contemporâneos nos campos da sociologia dos problemas públicos, da ação pública, da administração pública e da governança que se inspiram nas ideias do pragmatismo clássico e vão além dele focalizando nas noções de investigação pública e de experimentação democrática. 
atualidade, com vistas a contribuir para conceber novas perspectivas epistêmicas e vias de análise das políticas públicas. Mais particularmente, abordamos a herança e as contribuições mais recentes do pensamento pragmatista para compreender a "governança da ação pública". A noção implica um deslocamento da ideia de "governo" para "governança" e de "política pública" para "ação pública" (Dorf \& Sabel, 1998; Fung, 2002; Zimmermann, 2006, Lascoumes \& Le Galès, 2012; Shields; 2008; Briggs, 2008; Bohman, 2008; 2012; Sabel; 2012; Ansell, 2011; 2012).

No que se refere à análise das políticas públicas, isso significa uma (re)aproximação com uma concepção de democracia radical proposta por John Dewey, considerando a ideia de ação púbica como contraponto à noção de política pública em sua acepção racional e normativa tradicionalmente predominante no campo, desde a sua origem, com Harold Lasswell (1936). Isso pressupõe considerar a interconexão de escalas, de formas de regulação e de redes de atores que exigem uma "revisão das concepções estatistas de intervenção pública em benefício de análises mais abertas" (Lascoumes \& Le Galès, 2012: 17).

A política pública deixa então de ser interpretada enquanto programa estrito e intervenção racional, passando a ser compreendida como "experimentação" a ser observada quando colocada em prática; concebida como quebra-cabeça a ser resolvido, levando em conta a incerteza dos fins e do jogo de atores que as fazem acontecer na prática cotidiana. Trata-se de ir além da concepção de política pública como algo que pertence apenas ao Estado, de forma segmentada, entendendo que a consecução da ação pública se promove sempre a partir de "interações socioestatais" (Lavalle \& Swako, 2015), mesmo que não envolva necessariamente o protagonismo da sociedade civil.

Neste texto, partimos da ideia de que processos centrados na investigação e na experimentação dos problemas públicos - que em Dewey constitui a base para a consecução do Estado democrático - podem ajudar a compreender, e gerar oportunidades para fomentar dinâmicas em que diferentes públicos possam fazer parte e influenciar a governança das políticas públicas ou o artesanato político cotidiano. Ao parafrasear Daniel Cefaï (2012), as abordagens pragmatistas, pautadas no resgate da concepção de "público", parecem "reabrir" alguns canteiros de obras no campo da análise de políticas públicas, na medida em que a atenção se transfere dos dados oficiais e das instituições e normas para a trajetória dos problemas públicos, fazendo com que a coisa pública deixe de ser monopólio do governo, passando a ser inserida na vida cotidiana, a partir do enfrentamento de situações de prova diante dos problemas públicos experimentados. 
Para explorar tal perspectiva, este texto é estruturado em seis seções para além dessa introdução. Inicia com uma análise da literatura recente no campo da administração pública sobre governança e a análise das políticas públicas, evidenciando que esse debate remete a uma dupla dicotomia: entre modos de governar e de reformar o Estado e de formas de analisar as políticas públicas e seus efeitos. A partir das lacunas evidenciadas nesse debate, adentra-se na discussão sobre como a lente pragmatista pode lançar novas pistas para a agenda de pesquisa no campo, a partir das noções de experimentalismo democrático e de investigação pública. Busca-se aprofundar como tais noções podem ser inspiradoras para olhar de outra forma o "fazer política" cotidiano, sobretudo considerando os desafios atuais colocados por problemas públicos cada vez mais complexos em uma realidade de crise e retrocesso democrático em vários países, especialmente no Brasil. Nas considerações finais, apresenta-se um quadro síntese com algumas noções-chave que podem ser inspiradoras para fazer avançar a agenda de pesquisa no campo e para estudos que se interessam em analisar a governança das políticas públicas, a partir de enfoques pragmatistas.

\section{Do governo à governança:}

\section{superando as dicotomias para \\ a análise da ação pública}

No âmbito da administração pública e das políticas públicas, a crise das democracias traz à tona o debate sobre a redefinição do Estado democrático, dos estilos de governança e de produção da coisa pública. Como discute Chris Ansell (2011), a crise atual revela uma clivagem entre as formas de representação e regulação (que garantem mandatos legítimos) e as formas de governança (gestão e formas de resolver os problemas públicos). Isso faz com que emerja em vários países uma descrença quanto à capacidade da administração pública e das políticas públicas para responderem aos problemas públicos, cada vez mais complexos e multifacetados. Isso tudo vai ampliar o descrédito na política e na administração pública - bem como nos servidores públicos - muitas vezes entendidos como sinônimos de um "mal necessário" pelo cidadão médio, estando associados, em muitos discursos, à corrupção, à ineficiência e ao corporativismo. Isso faz, com que a administração pública seja vista e interpretada por muitos como estando fora de controle democrático e sendo vazia de moral (Ansell, 2011).

Para fazer face ao duplo colapso de governabilidade e de governança do Estado, vários países do mundo vão buscar reformá-lo a partir dos anos 1970. A literatura especializada distingue, entretanto, duas ondas de reformas (Pollitt \& Bouckaert, 2002), tendo por base modelos teóricos e práticas diferenciadas. Ansell (2012) e 
outros autores da administração pública, discutem esse movimento que vai culminar em uma oposição entre duas perspectivas reformistas do Estado exemplificados pelas narrativas do New Public Management - NPM (Nova Administração Pública) e do New Public Service - NPS (Novo Serviço Público).

O movimento do NPM se intensifica a partir da década de 1970, como contraponto ao modelo burocrático de administração pública e diante da crise do Estado de bem-estar social, uma vez que, segundo muitos de seus críticos, os dilemas atribuídos pelos limites fiscais e a incapacidade de regulação das questões públicas, o tornaram inviáveis. A perspectiva de reforma do Estado aqui preconizada privilegia a adoção de estratégias e técnicas de gestão embasadas na lógica de mercado, enfatizando a competição e o foco nos resultados (Andion, 2012). Há então uma ideia de separação entre política e técnica, resultando no avanço de uma perspectiva gerencialista da governança pública. As propostas do NPM avançaram rapidamente em uma época de ascensão das ideologias neoliberais, logo espalhando-se pelo Norte e pelo Sul globais (Motta, 2013).

No entanto, no decorrer desses mais de 30 anos, as políticas públicas, as estruturas, os processos de trabalho e os instrumentos gerenciais, aplicados à governança pública e seus efeitos, têm sido crescentemente questionados. De acordo com Paulo Roberto Motta (2013: 4), "o otimismo e o entusiasmo inicial com o NPM reduziram-se, não por decepção ideológica, mas pelo fracasso nos resultados e na qualidade do serviço público." Como discutido por vários estudos, mesmo quando mais empresariais, menos onerosas e mais eficientes, as administrações públicas não se tornaram mais favoráveis aos cidadãos após as reformas gerenciais (Motta, 2013; Kissler \& Heidemann, 2006).

A partir dessas críticas, o NPS se estabelece como contraponto e novo "modelo" de reforma, ainda na década de 1990. O foco central dessa perspectiva é servir ao interesse público entendido como o "resultado do diálogo sobre valores compartilhados" (Denhardt \& Denhardt, 2003: 67). Aqui, o engajamento do cidadão nas decisões públicas, de forma ativa e atuante, é colocado como fator preponderante. De acordo com Janet Denhardt e Robert Denhardt (2003) o NPS é inspirado no ideal de democracia participativa, preocupando-se em reafirmar a conexão entre os cidadãos e seus governos. A partir dessa leitura, a administração pública "andaria de mãos dadas" com os cidadãos de forma responsiva e construtiva por meio de uma estrutura dinâmica, criativa e inovadora capaz de se antecipar aos problemas.

Embora a perspectiva do NPS resgate a integração entre as dimensões política e administrativa, sua narrativa se caracteriza por conceber a administração pública 
a partir de uma perspectiva normativa e idealizada que aparece como positiva e natural (Motta, 2013), assim como no discurso do NPM. Tal crítica é destacada por autores como Chris Ansell (2012) e Berk (2012), que nos convidam a olhar para as práticas e sair da armadilha da naturalização dos modelos ideais como saída para repensar a administração e a governança públicas, já que esses por si mesmos não respondem à resolução dos complexos problemas colocados às democracias, conforme discutido brevemente nessa introdução.

Ansell (2012) argumenta que apesar do avanço nas discussões no campo da gestão pública, as dicotomias e dualismos se tornam pouco produtivos para a compreensão das dinâmicas de governança e na análise das políticas públicas. Nessa mesma linha, Xavier Briggs (2008) destaca que soluções inovadoras para os problemas nas sociedades democráticas exige formas mais multidimensionais de ação e prestação de contas, envolvendo combinações hábeis de aprendizado e negociação por atores cívicos, indo além da retórica contemporânea do "agir em parceria" ou produzir política "de baixo para cima". Como complementação, James Bohman (2008) e Ansell (2012) adicionam que tais modelos normativos e prescritivos acabam por encalhar tanto na teoria como na prática e suas experiências se tornam parte do próprio problema da administração pública na atualidade.

Diante disso, na tentativa de responder aos desafios atuais e transcender a oposição entre os clássicos modelos normativos, diversos autores têm buscado inspirações tanto do pragmatismo clássico americano, o qual possui como figura central o filósofo John Dewey, como também em autores pragmatistas contemporâneos, acessando novos prismas para repensar a administração pública, as políticas públicas e sua governança.

Ao seguirmos essas pistas, nos concentraremos neste texto em promover o diálogo entre dois campos disciplinares para imprimir um novo olhar sobre a administração pública, a governança e a análise das políticas públicas. Primeiramente, nos inspiramos nos autores da sociologia dos problemas públicos que tratam dos processos de investigação pública, inspirados no trabalho precursor de John Dewey (Bovet \& Terzi, 2012; Cefaï, 2002; 2009; 2011; 2016; 2017; Cefaï \& Terzi, 2012; Chateauraynaud, 2011; Frega, 2019; Joseph, 2004; Karsenti \& Quéré, 2004; Quéré \& Terzi, 2015; Stavo-Debauge, 2012; Stavo-Debauge \& Trom 2004; Terzi, 2015; Zask, 2004).

Recorremos também a diversos estudos recentes no campo da administração pública que (re)discutem a gestão pública, a governança pública e a análise das políticas públicas fundamentados nos pragmatismos, com destaque para: Ansell (2011; 2012); Ansell, Sørensem e Torfing (2020); Bohman (2008; 2012); Briggs (2008); Dorf 
e Sabel (1998), Zimmermann (2006); Lascoumes e Le Galès (2012), Sabel (2012), Sabel e Zeitlin (2011). Esses autores exploram a perspectiva de análise oferecida pelo "experimentalismo democrático", trazendo pistas importantes para compreender os processos de governança e as política públicas enquanto estes fenômenos estão ocorrendo, e seus respectivos dilemas, concentrando-se na ação pública, como será mais explorado a seguir.

\section{Pragmatismos e a sua contribuição para um novo olhar para o Estado e a administração pública}

Aproximar os pragmatismos da administração pública e da análise da governança pública exige recuperar a herança da teoria da democracia radical proposta por Dewey (1927), que tem como ponto de partida a crítica à visão normativa do Estado e da própria democracia. O autor rejeita a interpretação "burocrática" ou "estatística" da democracia, baseada na ideia de maioria, encarando-a como um verdadeiro "modo de vida" (Stavo-Debauge \& Trom 2004: 197). A experiência compartilhada é um bem valioso para John Dewey, pois lugar de realização individual, de promoção de autonomia, de formação e de aprendizagem do viver junto. Como salienta Cefaï (2017), havia nesse momento uma "indagação social" que significava não apenas um sinal de modernização - com a difusão do espírito científico, da especialização e da tecnologia -, mas também a prática de intervenções a valorizarem as potencialidades do ambiente, numa perspectiva de concretizar os fins no intuito de promover melhorias na qualidade de vida das populações. Este era o sentido dos social survey na época e, em seguida, na pesquisa sociológica seja no trabalho social ou na política urbana dos anos 1920 promovida pelos sociólogos de Chicago.

Atualmente, passados quase cem anos, certamente o cenário das democracias se modificou enormemente, como discutido anteriormente, ampliando em muito o efeito da Great Society, denunciado por Dewey em seu livro The public and its problems, o que leva a formação de sociedades que são verdadeiros mosaicos, permeadas por desigualdades de vários tipos e compostas de públicos dispersos, móveis e plurais. Isso ainda é mais desafiador em países em desenvolvimento e de baixa renda, com fortes desigualdades, como o Brasil, no qual a ideia de público se coloca como verdadeira utopia, diante, até mesmo, da invisibilidade de muitos grupos e vozes. Tudo isso levanta uma série de questões sobre os alcances da democracia em suas diferentes matrizes, seja ela representativa, participativa ou deliberativa. Por outro lado, o cenário atual lança também pistas para novos entendimentos sobre a prática democrática cotidiana, que, nas palavras de Claude Lefort 
(1986), é sempre uma obra inacabada, cujo sentido do que vem depois estará sempre em suspenso e será construído, com os desafios, os limites e as possibilidades dos espaços públicos nos quais essas democracias se inscrevem.

É diante de uma nova compreensão desse processo de "fazer política" que as ideias de Dewey parecem ganhar um novo fôlego. Mas essa retomada do pensamento Deweyano se dá, sob novas bases e lentes, considerando as importantes mudanças ocorridas nas últimas décadas nos sistemas políticos e nas práticas democráticas e na própria administração pública. Nesse sentido, gostaríamos inicialmente de discutir algumas noções-chave do pensamento pragmatista de Dewey, as quais vêm sendo resgatadas e discutidas por autores contemporâneos e que podem ser inspiradoras para (re)significar e lançar novas pistas para o estudo da administração pública, da governança e a análise das políticas públicas, como será discutido adiante.

Esse resgate das ideias de Dewey pelos autores contemporâneos destaca uma primeira noção central que diz respeito à importância de focalizar na resolução dos problemas públicos. De acordo com Ansell (2011), numa leitura pragmatista, o aprendizado coletivo e colaborativo é "orientado a problemas". Tal perspectiva reflete a ênfase na relação adaptativa entre os seres humanos e seu ambiente natural e cultural. Segundo o autor, ao desafiar o conhecimento e a experiência estabelecidos, os problemas públicos também oferecem oportunidades críticas para a aprendizagem. Eles estimulam o questionamento e incentivam as pessoas a desenvolverem estratégias criativas para a solução das questões que vivenciam. O foco em problemas concretos também serve como estratégia frutífera para a interação política produtiva. Embora uma abordagem orientada a problemas não dissolva magicamente diferenças ou valores políticos, nem a cultura política, e os substitua por investigações racionais (Festenstein, 2001), o foco nos problemas pode ajudar as partes opostas a evitar disputas improdutivas e dogmáticas.

Uma segunda noção central na obra de Dewey e de outros pragmatistas clássicos recuperada pelos autores contemporâneos é a centralidade da experiência. De acordo com Maria Cristina Ferreira (2011), a noção de experiência está intimamente relacionada ao conjunto dos nossos sentidos, e estes, por sua vez, interagem com a cognição de um agente. No entanto, para Dewey (1956), a noção de experiência ultrapassa essa visão "cognitivista", colaborando com a instauração ou na manutenção de hábitos. Dessa maneira, a experiência passa a ter relevância nas atividades cotidianas, principalmente através dos conhecimentos acumulados, uma vez que a experiência não se limita ao ato no presente, mas também remonta ao que foi aprendido no passado (incluindo as memórias) e se reporta ao futuro. 0 
ponto central para Dewey não é o sujeito nem o objeto, nem a natureza ou o espírito, mas as relações entre eles: e a experiência é o lugar central dessa interação. As ideias e os fatos não existem fora da experiência (Dewey, 1956).

Uma terceira noção importante e relacionada à noção de experiência trata da indagação/inquirição/investigação. É no livro Lógica, a teoria da investigação, publicado já no final de sua vida, que Dewey dispõe integralmente a sua teoria da investigação, problematizando a lógica e contextualizando-a em sua teoria, relacionando-a com suas concepções filosóficas, educacionais e sociais. A teoria da investigação ou, como Dewey a denominou, a lógica, de acordo com Maria N. Amaral (2007), não consiste em uma teoria no seu sentido abstrato, ou seja, em analogias dedutivas entre enunciados, mas sim numa teoria que versa sobre a relação dos seres humanos com seus ambientes, destacando assim a importância da experiência situada e do processo de experimentação.

Como dispõe Caio Cabral (2014), o que consiste no ato de investigar para Dewey é a conexão entre o pensamento reflexivo e a inquirição objetiva. $\mathrm{O}$ ato de investigar passa a ser então entendido como o artifício adequado para viabilizar o conhecimento válido, ou seja, um conjunto de "asserções garantidas" experimentalmente e de caráter progressivo. No entanto, o processo investigativo não se limita apenas à observação e à experimentação em si, mas também leva em conta as teorias, os conceitos, as formas lógicas e o próprio conhecimento, os quais emergem do próprio processo de pesquisa e de experimentação, servindo como instrumentos para o decorrer do próprio ato investigativo ou para novas investigações com o intuito principal de solucionar situações problemáticas. O conhecimento é compreendido pelo autor como solução prática de situações problemáticas que são vivenciadas na natureza. Essa solução é encontrada pelo processo de investigação colocado em prática pelas pessoas, sendo o conhecimento então o "término apropriado da investigação" (Dewey, 1956: 8).

Esse conhecimento então torna-se instrumento possível de manipulação pelas pessoas experimentalmente, ou "utilizados na condução de novas investigações em novas situações problemáticas" (Dewey, 1956: 119). Apesar da importância dada pelo filósofo à ciência, o processo de investigação para ele está relacionado também e sobretudo aos problemas gerais da vida cotidiana. Para Dewey (1956), o processo investigativo em torno das situações problemáticas geralmente ocorre de forma coletiva, uma vez que as pessoas, isoladamente, pouco podem fazer para satisfazer às suas condições de vida, já que essa ocorre em sociedade. Assim, o filósofo destaca que os conhecimentos e a inteligência advindos desse processo de investigação é algo experimental e construtivo, que se desenvolve a partir das con- 
tribuições das diversas pessoas e, por esse motivo, é capaz de gerar conhecimentos com maior qualidade.

Assim, o conhecimento deriva da associação e da comunicação, o que torna possível, mesmo que de forma indireta, influenciar o processo de reconstrução de hábitos em alguma direção determinada. As noções de experiência e de investigação em torno de problemas tornam-se centrais na teoria democrática de Dewey, pois a centralidade da experiência e da investigação em torno dos problemas públicos é essencial para a formação dos públicos, o que consiste para o filósofo a base estruturante do Estado democrático.

Para o autor, o fortalecimento do Estado democrático está relacionado com a formação dos "públicos", que surgem da experiência associativa e da consideração das consequências dessa experiência. Assim, Dewey (1927: 131, grifo nosso) argumenta que "o alicerce do desenvolvimento do Estado é o reconhecimento público dos problemas da ação associada", que acontece na prática diária. Em outras palavras, é a constituição de interesses comuns e sua publicização, ou seja, constituição dos públicos, que cultivam as bases da democracia. "O público, portanto, é constituído por todos aqueles que se veem afetados pelas tramas sociais e, por conta disso, encontram-se forçosamente envolvidos com outros com quem compartilham o desenvolvimento das consequências".

Cefaï (2017) retoma essa noção de público entendida como comunidade que se constitui em torno de "public issues" (questões públicas); o que reengendra um mundo que, por mais dividido que seja, nos cabe em comum. Esse processo pode gerar oportunidades para que os públicos influenciem nas trajetórias de seus territórios e na construção de novos futuros possíveis. É nessa dinâmica de constituição do público, de reconhecimento da situação problemática e de suas consequências na busca de respostas para tais problemas, que se constitui a investigação pública. Para Cefaï (2017: 189), essa capacidade de investigação, que não é exclusiva de especialistas, refere-se "à condição dos públicos de perceberem a consequência de situações problemáticas, nomeá-las, identificá-las, interpretá-las, construir conhecimento e propor soluções para elas". Nesse sentido, os cidadãos comuns são capazes de uma "atitude de cognição" (Cefaï, 2016: 24) e de adotar métodos para fazer frente aos problemas públicos, ou seja, eles são capazes de fazer política pública.

Mas como tais noções, brevemente exploradas aqui, se aplicam e podem ajudar na análise da governança e das políticas públicas? A seguir discutimos mais de perto essa questão, buscando evidenciar como as noções de investigação pública e experimentação podem ser empregadas na análise das políticas públicas. 


\section{Explorando o campo das políticas públicas e as contribuições da perspectiva pragmatista de análise}

O campo de análise de políticas públicas tem sua origem intrinsecamente relacionada ao pragmatismo clássico, já que um dos "pais" fundadores do campo e criador do termo - Harold Lasswell (1902-1978) - estudou na Universidade de Chicago e foi fortemente influenciado pelas ideias de John Dewey. Entretanto, a perspectiva mais "pragmática" do que "pragmatista" que inaugura o campo de análise de políticas públicas vai claramente se afastar da noção de democracia radical e das propostas de Dewey, brevemente exploradas acima, e se filiar mais a uma abordagem funcionalista (na qual Lasswell também se inspirava), buscando fazer com que o conhecimento acadêmico direcionasse a prática dos governos, num viés de modernização e regulação social (Lascoumes \& Le Galès, 2012).

Com a consolidação do campo, embora novas perspectivas analíticas emerjam, esse viés normativo-prescritivo se fortalece e assume papel preponderante, ganhando a etiqueta de análise racional de políticas públicas (Boullosa, 2013). Conforme discutem Frank Fischer, Gerald Miller e Mara Sidney (2007: 14), até os anos 1960 tal perspectiva racional predominava e "os problemas públicos e as políticas públicas existiam como fatos a serem apreendidos pelo analista, a partir da utilização do método científico, conduzindo à hegemonia de uma abordagem positivista".

Essa perspectiva expandiu-se no campo a partir da década de 1960, com a propagação de teorias que postulavam estratégias de maximização dos interesses, da racionalização e do princípio da eficiência para direcionar as ações governamentais (Lascoumes \& Le Galès, 2012). Com o passar dos anos, novas abordagens, conceitos e entendimentos foram sendo desenvolvidos, configurando o campo como difuso, permeados por diversas abordagens teóricas e modelos. Isso se reflete na própria interpretação da política pública que pode ser definida e compreendida a partir de diferentes lentes, dependendo do autor de referência, como exemplificado no Quadro 1.

Essa amplitude de definições ilustra como o campo de análise de políticas públicas vem se expandido consideravelmente nas últimas décadas, tanto no contexto internacional quanto no Brasil (Souza, 2007). Diversas são as perspectivas de estudos nesse campo, indo de leituras mais teóricas e gerais, centrando-se na discussão das definições dos conceitos, paradigmas, teorias e abordagens analíticas, até questões mais específicas e empíricas, incluindo o ciclo de gestão das políticas públicas, envolvendo seu planejamento, implementação e avaliação. Com isso, especialmente a partir dos anos 1970, emerge uma série de estudos que se contrapõe e faz uma crítica à análise racional de políticas públicas. 
QUADRO 1

DEFINIÇÕES SOBRE AS POLÍTICAS PÚBLICAS NA LITERATURA

\begin{tabular}{|c|c|}
\hline Autor & Definição e dimensões de análise \\
\hline Thoenig (1973) & $\begin{array}{l}\text { Designa as intervenções de uma autoridade investida em poder público e de legitimidade } \\
\text { governamental sobre um domínio específico da sociedade ou do território. }\end{array}$ \\
\hline Dye (1976) & Tudo aquilo que os governos escolhem fazer ou não fazer. \\
\hline Lipsky (1980) & Atividade de execução, elaborada pelos burocratas de rua. \\
\hline Lynn (1980) & Conjunto de ações do governo que irão produzir efeitos específicos. \\
\hline Muller (1989) & $\begin{array}{l}\text { Uma forma de institucionalização da divisão do trabalho governamental [...], operação de } \\
\text { recorte do real, através da qual a substância dos problemas a serem enfrentados ou a natureza } \\
\text { das populações afetadas serão delimitadas e formatadas. }\end{array}$ \\
\hline March (1991) & Heterogeneidade das sequências das ações, sua combinação aleatória e racionalização. \\
\hline Rose (1994) & $\begin{array}{l}\text { Um programa de ação governamental que consiste numa combinação específica de leis, } \\
\text { destinação de recursos financeiros, administrativos e humanos para a realização de objetivos } \\
\text { mais ou menos definidos com clareza. }\end{array}$ \\
\hline Commailles (1999) & Espaço de negociação de interesses sociais. \\
\hline Considine (2005) & Interações entre atores e instituições. \\
\hline Page (2006) & $\begin{array}{l}\text { Combinação de quatro elementos: uma representação geral sobre a maneira de conduzir os } \\
\text { negócios públicos, prioridades específicas, decisões e instrumentos e comportamento dos } \\
\text { funcionários em realizar as medidas estabelecidas. }\end{array}$ \\
\hline Dryzek (2006) & Discursos de convicção. \\
\hline
\end{tabular}

Fonte: Elaborado pelos autores, com base nos autores citados.

Sem adentrar numa discussão aprofundada da multiplicidade de abordagens e modelos de análise de políticas públicas, o que fugiria do escopo deste ensaio, apresentamos a seguir, no Quadro 2, uma síntese das principais abordagens teóricas predominantes no campo, seus aspectos centrais e os principais autores, o que evidencia o predomínio das abordagens racionais-legais de análise, apesar da diversificação epistemológica e paradigmática do campo nas últimas décadas.

Essa constatação é confirmada por Michael Howlett, M. Ramesh e Anthony Perl (2013), que, ao fazerem uma análise epistemológica do campo de estudos sobre as políticas públicas, destacam duas principais vertentes: a análise racional de políticas públicas (policy analysis) e os estudos sobre políticas (policy studies). A primeira vertente, segundo os autores mais tradicional, ancora-se numa concepção positivista e racional que compreende a política pública enquanto fato, expressada a partir das ações governamentais, caracterizando a centralidade do governo e a perspectiva hierárquica de cima para baixo. O foco da análise está na avaliação formal, racional e neutra dos resultados (outputs) e do impacto (outcomes) das políticas, a partir de métodos quantitativos, preocupando-se, assim, mais com os fins do que com o processo. Essa abordagem tem sido muito aplicada nos estudos da administração pública no Brasil, a partir de uma orientação racional-instrumental, considerada por Rosana Boullosa (2013) como resultado da forte influência da corrente norte-americana nas escolas de administração pública do país. 


\begin{tabular}{|c|c|c|}
\hline $\begin{array}{l}\text { Abordagens } \\
\text { teóricas dominantes }\end{array}$ & Aspectos centrais das teorias & Autores \\
\hline Racional & $\begin{array}{l}\text { Problema como fato a ser apreendido pelo pesquisador a partir de } \\
\text { procedimentos científicos. Comparação exaustiva de alternativas, com } \\
\text { base em análise de custo-benefício. Ciclo de política pública como uma } \\
\text { sucessão lógica e cronológica de etapas. A formulação (decisão) é muitas } \\
\text { vezes considerada como a etapa fundamental do processo, da qual } \\
\text { decorre a implementação (abordagem top-down da implementação). A } \\
\text { política escolhida é vista como "a" melhor alternativa. }\end{array}$ & Lasswell (1936) \\
\hline Racionalidade limitada & $\begin{array}{l}\text { Existência de limitações informacionais e cognitivas na definição do } \\
\text { problema e no estudo de alternativas. A política escolhida é a melhor } \\
\text { diante das informações disponíveis e da capacidade de processamento } \\
\text { de informações no estudo de alternativas. }\end{array}$ & Simon (1972) \\
\hline $\begin{array}{l}\text { Incrementalismo } \\
\text { e Teoria do Ótimo } \\
\text { Normativo }\end{array}$ & $\begin{array}{l}\text { Influência de fatores políticos e de valores no estudo de alternativas. } \\
\text { Limitações de tempo e de recurso dificultam o estudo exaustivo de } \\
\text { alternativas. As comparações se dão como um processo sucessivo e limi- } \\
\text { tado. A alternativa é escolhida com base em um processo de tentativa e } \\
\text { erro. O processo de formulação é incremental. A alternativa é a possível } \\
\text { (inclusive considerando fatores políticos) e não "a melhor" e ótima. } \\
\text { Influência de fatores extrarracionais. }\end{array}$ & $\begin{array}{l}\text { Easton (1953; } \\
\text { 1965); } \\
\text { (Lindblom, 1959); } \\
\text { Baratz e Lukes } \\
\text { (1963); } \\
\text { Etzione, Lowi e } \\
\text { Barch (1969) }\end{array}$ \\
\hline Garbage Can & $\begin{array}{l}\text { Inversão da sequência problema-solução. Diante de limitações das } \\
\text { capacidades estatais, os gestores escolhem o problema a ser "resolvido". } \\
\text { Soluções desenvolvidas anteriormente são buscadas numa "lata de lixo" } \\
\text { para solucionar o problema escolhido. }\end{array}$ & $\begin{array}{l}\text { Cohen, March e } \\
\text { Olsen (1972) }\end{array}$ \\
\hline $\begin{array}{l}\text { Neo-institucionalismo: } \\
\text { a Escolha racional } \\
\text { a Sociológico } \\
\text { a Histórico }\end{array}$ & $\begin{array}{l}\text { Os atores que tomam a decisão (formuladores) - selecionando a } \\
\text { alternativa a ser adotada - são condicionados por instituições formais e } \\
\text { informais (regras, incentivos etc.). }\end{array}$ & $\begin{array}{l}\text { Katznelson (1981); } \\
\text { Thelen; Steinmo, } \\
\text { (1992); } \\
\text { Skocpol (1992); } \\
\text { Hattan (1993); } \\
\text { Evans (1993); } \\
\text { Limongi (1994); } \\
\text { Immergut, (1998); } \\
\text { Hall; Taylor (2003) }\end{array}$ \\
\hline
\end{tabular}

Quanto à segunda vertente, os autores a caracterizam como antipositivista, permitindo a ampliação na compreensão da política pública e em suas dimensões de análise, baseando-se numa visão mais interpretativa dos processos de política pública e destacando o seu caráter político. De forma diversa da concepção racional, destacam que há uma série de determinantes e condicionantes que influenciam os processos de políticas públicas e, consequentemente, os seus resultados e, por conseguinte, buscam examinar não apenas os efeitos das políticas e programas públicos, mas também suas pressuposições, seus processos, bem como o conteúdo das políticas que estão imersas em sistemas políticos (Howlett, Ramesh \& Perl, 2013).

Dito isso, pode-se constatar aqui a mesma polarização criticada por Ansell (2011) no campo da administração pública, que leva a privilegiar análises pouco capazes de levar em consideração as múltiplas dimensões e escalas das políticas públicas, bem como examiná-las in situ, sendo gestadas - já que privilegiam modelos normativos 
e prescritivos e focalizam pouco os processos de enfrentamento dos problemas públicos na prática - a partir de sistemas de governança multiatores e multisetores.

Diante dessas lacunas, acredita-se que as lentes pragmatistas, brevemente exploradas na sessão anterior, permitem conceber uma perspectiva diferenciada para a análise das políticas públicas, permitindo acompanhar - in vivo - a experiência processual da ação pública coproduzida por múltiplos atores em diferentes escalas espaciais e temporais e em diferentes situações vivenciadas. Trata-se aqui, não de negar as abordagens anteriores, mas colocá-las para dialogar, fixando o foco principalmente sobre a governança das políticas, nos processos e dinâmicas de investigação pública e nas experimentações democráticas (Ansell, 2011; 2012; Berk, 2012; Frega, 2019) que ocorrem nas arenas públicas, como será explorado na próxima seção.

\section{Análise pragmatista de políticas públicas: investigação pública e experimentação democrática em arenas públicas}

No campo da administração pública, as perspectivas pragmatistas de análise têm sido resgatadas por diferentes atores, ganhando força principalmente a partir de década de 1990. Michael Dorf e Charles Sabel (1998), ancorados no trabalho de Dewey, advogam por uma nova forma de compreender a governança pública a partir do experimentalismo democrático, na qual prevalece um processo de descentralização do poder para permitir que cidadãos e outros atores utilizem seu conhecimento local para encontrar soluções para suas circunstâncias individuais, assim como para as coletivas.

Patricia Shields (2008: 5), por sua vez, resgata as noções de investigação pública e experimentação, defendendo que tais noções fornecem uma lente útil para mostrar como a democracia participativa pode nutrir um serviço público criativo e colaborativo, uma vez que, junto com os demais atores, os administradores públicos podem examinar com mais eficiência como eles abordam os problemas, consideram os dados e se comunicam. Além disso, a autora salienta que tais noções "também reconciliam algumas das controvérsias importantes na administração pública, como a dicotomia prática/teoria, o papel da especialização e as formas de incluir a democracia na prática".

Ao resgatar a ideia central de democracia como resposta de determinados problemas, Briggs (2008) argumenta que a teoria e a prática da democracia (e o que a faz funcionar) incluem, necessariamente, o estudo da solução de problemas em ação e 
a capacidade coletiva de resolver problemas. Isso não apenas para deliberar sobre o mundo e definir rumos para o governo, mas para mudar o estado do mundo, por meio da ação coletiva; ou seja, não apenas para decidir, mas para fazer. O autor destaca a importância de a administração pública considerar a ação pública local no enfrentamento dos problemas públicos, uma vez que é possível construir formas efetivas de capacidade cívica, mesmo quando a história não dota o lugar com uma tradição de cooperação cívica ou confiança generalizada em instituições públicas.

A ação pública é assim coproduzida no encontro de diversas ações coletivas que se encontram e assim podem forjar a ordem social e política, a direção da sociedade, a regulação de suas tensões, a coordenação dos grupos e resolução dos conflitos (Lascoumes \& Le Galès, 2007). Nesse sentido, a ação pública engloba as políticas públicas, mas não se reduz a estas. Como sugere Luís Miguel Carvalho (2015), a política pública pode ser analisada focalizando os entes governamentais, mas também pode ser vista e examinada, no próprio curso da ação social, indo além do governo.

Consequentemente [...] a adoção do prisma da ação pública altera a perspectiva e a focalização das políticas públicas. E essa alteração pode ser associada a dois grandes planos: o da ampliação dos contextos de ação - e de atores - que são tomados como significativos para a análise das políticas; o da ruptura com visões lineares e verticais das políticas públicas e seus processos (Carvalho, 2015: 317).

Nessa mesma linha, Ansell (2011), ao discutir sobre as democracias modernas, parte da concepção deweyana da democracia e salienta que a análise das instituições representativas tradicionais são insuficientes diante da complexidade dos problemas socioambientais vivenciados na atualidade. O autor resgata alguns pensadores pragmatistas, como John Dewey, Mary Parker Follet e Jane Addams, que já salientavam que as instituições públicas precisam complementar os canais tradicionais de representação com formas mais diretas e deliberativas de construção de consentimento, com foco na resolução de problemas públicos. Nesse sentido, o autor argumenta que as organizações públicas podem servir como vetor importante de fortalecimento da democracia, porque podem construir o consentimento da sociedade para as políticas, por meio da resolução eficaz de problemas locais junto aos públicos e do redesenho das instituições.

Os autores citados trazem, a nosso ver, importantes contribuições para análise das políticas públicas e sua governança, ao salientarem a importância das "experimentações democráticas", que podem emergir de dinâmicas de investigação pública anteriormente exploradas e, assim fazendo, podem contribuir para relacionar as 
dimensões institucionais da regulação e da legitimidade com a dimensão da resolução dos problemas na administração pública (Fung \& Wright, 2003; Bohman, 2004; Shields, 2008; Briggs, 2008; Ansell, 2012; Frega, 2019).

Em virtude dessa mesma compreensão em seu livro Pragmatismo e uma visão ampla da democracia, de 2019, Roberto Frega recoloca a questão da crise das democracias liberais discutida na introdução desse artigo. Para o autor, essa crise vai muito além de uma crise apenas institucional-legal (de procedimentos). Ela também não se resume a uma crise de regimes de governança ou ao mero esvaziamento da substância "participativa" da democracia. Para Frega (2019), o desafio passa por (re)pensar e (re)construir a forma como entendemos e olhamos as democracias. Trata-se de considerá-las como democracias para além de seu aspecto formal, vistas enquanto combinações de instituições e regras que traduzem fielmente os anseios populares na política. Isso significa considerar as potencialidades dos diversos padrões de interação social ou de ação pública que compõem as democracias enquanto fonte de ação criativa, de inovação social e de transformação do instituído.

Compreender os processos de experimentação democrática nas ações públicas é proposto por esses autores como caminho para entender como ocorre - ou não a interface entre as democracias e os processos de inovação social (Frega, 2019), ou seja, como os diversos "públicos" se engajam em processos para fazer face aos problemas públicos e reinventar o instituído. Para complementar, Ansell (2012) destaca que a perspectiva pragmatista não assume que a transformação/inovação vá ocorrer e, por isso, o foco das análises é mais o de compreender e fomentar as condições para que essas transformações possam acontecer.

Chris Ansell (2012) e Roberto Frega (2019) destacam, nesse sentido, a centralidade das instituições, que nessa concepção podem ser acessadas não apenas pela análise dos dispositivos e instrumentos (leis, normas, regras, rotinas, procedimentos e convenções sociais), mas a partir de interações sociais que constituem, no cotidiano, as democracias. As instituições, sejam elas sociais ou políticas, são um dos pilares da concepção pragmatista de democracia, já que uma sociedade cujas instituições não estão devidamente democratizadas constitui-se uma sociedade antidemocrática. Este julgamento diz respeito ao mesmo tempo às instituições particularmente, mas não exclusivamente políticas - como possíveis agentes de democratização da sociedade e como locais onde a vida social pode se desenvolver, de acordo com padrões democráticos (Frega, 2019: 272).

Assim, os autores chamam atenção para a importância do desenho das instituições na prática ou esse "artesanato democrático" e seu potencial de, ao mesmo tempo, 
fortalecer os hábitos democráticos e promover diferentes formas e espaços de interações sociais nos diversos níveis da vida social. Por outro lado, essa "experimentação" pode contribuir para identificar, articular e resolver problemas sociais concebidos como problemas dos "públicos", ou seja, problemas que o cidadão comum considera digno de resolução (Frega, 2019).

Apesar de a literatura sobre experimentação democrática claramente priorizar as instituições e organizações como agentes de inovação social, existe uma diversidade de formas de experimentação social que ocorre fora de ambientes institucionais e organizacionais. Assim, o processo de democratização amparado na inovação social relaciona-se à criatividade e ao potencial inovador de "formas diversas, mas não menos significativas, formas de experimentação social que ocorrem onde novas linguagens, novos quadros interpretativos, novas visões para o futuro estão constantemente em formação" (Frega, 2019: 302).

Portanto, tal perspectiva de um "experimentalismo democrático" defendida por Frega (2019: 287), amparada na investigação pública, pode possibilitar compreender de outra forma as políticas públicas e sua governança, ajudando a construir vias para torná-las mais reflexivas, efetivas, democráticas e legítimas, questões centrais no cenário de retrocesso democrático que vivenciamos. Trata-se de processo contínuo de "experimentar" que pode gerar um potencial de inovação social e novos regimes de ações coletivas, de governança das políticas públicas, de ação pública e de interações socioestatais.

Para o autor as instituições são experimentalistas na medida em que:

i. aumentam as oportunidades de experimentar soluções alternativas para problemas complexos;

ii. institucionalizam o exercício da dúvida voltado para o questionamento permanente das rotinas;

iii. enfatizam que os experimentos de teste têm, em primeiro lugar, validade local porque estão enraizados em problemas cuja forma não é universal, mas depende de variáveis contextuais; e

iv. definem procedimentos padrão para permitir a comparação de dados produzidos, de acordo com procedimentos homogêneos, preservando a autonomia local e, ao mesmo tempo, possibilitando a aprendizagem coletiva.

Democráticas pois: 
i. por meio da descentralização, aumentam a chance de que aqueles que são afetados por um problema possam participar da busca de soluções;

ii. promovem ampla inclusão, ampliando a participação desde a percepção inicial de um problema até o momento final da tomada de decisão em todo o processo de investigação social; e

iii. valorizam os recursos epistêmicos dos atores locais, impulsionando ativos ao invés de envolvimento passivo em práticas e instituições sociais.

Cumpre lembrar que o experimentalismo democrático não é algo natural na administração pública, nem conquistado de uma vez por todas, mas sim algo que está em constante construção e, por esse motivo, exige constante engajamento ante as mudanças e situações desafiadoras. O processo de "inquirição" é aprendido enquanto exercitado e, dessa maneira, requer esforço na construção de práticas e hábitos de indagação e de construção de aprendizado social.

Outra questão também destacada pelos autores é que o aprendizado social e as experiências de experimentação democrática requerem, necessariamente, a inclusão social e a constante reflexividade. Logo, diante dessas características, torna-se importante o fortalecimento das redes, do envolvimento de diferentes públicos, especialistas e leigos, do centro e da periferia, com maior e menor poder, favorecendo a pluralidade, a coconstrução de conhecimento, a partir do encontro de saberes e de aprendizagem colaborativa (Ansell, 2012; Frega, 2019).

Para complementar, Frega (2019) destaca:

As decisões tenderão a afetar diferentes grupos de formas diversas, de modo que sua legitimidade e eficácia requerem efetiva inclusão nos processos de investigação e, em certa medida, nos processos de gestão (Frega, 2019: 299).

Em outras palavras, o autor refere-se à necessidade da construção de modos de governança colaborativa dos problemas e dos projetos de reforma e gestão dos recursos coletivos. Ansell (2012) também destaca que a governança colaborativa é fundamental para processos de experimentação, pois pode promover processos reflexivos, criativos e geradores de aprendizagem diante dos problemas enfrentados e, assim, o passo intermediário entre a definição e a solução do problema é o próprio processo colaborativo de investigação e experimentação. 
Diante disso, acreditamos que focalizar nos processos de investigação pública/experimentação democrática pode ser frutífero para a análise das políticas públicas e sua governança, uma vez que, como destaca Frega (2019), tais processos podem permitir integrar ambas as dimensões da democracia: a participação na tomada de decisões e o envolvimento na solução de problemas, ou seja, trata-se não somente de influenciar as agendas políticas, mas de envolver-se na construção/implementação concreta das políticas; compreendendo a política enquanto essa é exercida, vivida, "en train de se faire" (sendo feita).

Com base nas considerações feitas até aqui, acredita-se que uma análise pragmatista das políticas públicas pode contribuir para compreender melhor como ocorrem as dinâmicas de investigação pública e experimentação democrática na governança das políticas, seus alcances, limites e seus efeitos. A seguir, no Quadro 3, buscamos delinear as diferenças e contribuições dessa abordagem analítica em relação às vertentes positivistas e antipositivista anteriormente exploradas.

Uma análise pragmatista considera, então, que as políticas públicas, compreendidas pela lente da "ação pública" são promovidas por diferentes atores em resposta aos problemas públicos vivenciados. Essas têm como locus central a esfera pública, que passa a ser compreendida sob uma outra ótica, diferentemente daquela tradicionalmente concebida por Jürgen Habermas (1984). Cefaï (2017) argumenta que, atualmente, os espaços públicos são mais híbridos, dinâmicos e até mesmo virtuais, caracterizados por múltiplos atores em interação. O autor propõe então compreendê-la a partir da noção de "arena pública" (Cefaï, 2002) que vai além dos dispositivos institucionais, técnicos ou jurídicos da ação pública e dos espaços de posições estruturadas de um campo político. É um espaço de combate, de disputas, mas também de construção de acordos, realizações e performances que promovem efeitos em termos de ação pública.

Nas arenas públicas, podem se engajar - ou não - uma multiplicidade de atores, a partir de uma pluralidade de regimes de engajamento e interesses, o que pode gerar processos de investigação pública em torno das situações problemáticas vivenciadas. Logo, destaca-se a importância de uma visão multicêntrica, que permita considerar a diversidade e a pluralidade de atores e de suas interações nas arenas públicas.

Outra questão importante na visão pragmatista é que, apesar de o foco de análise estar na ação pública situada/territorializada, dá-se lugar para a análise de diferentes escalas em que o problema público e a política pública se constituem, ou seja, torna-se central compreender como as decisões e as ações que se estabelecem em 
QUADRO 3

PRINCIPAIS ABORDAGENS DE ANÁLISE

DAS POLÍTICAS PÚBLICAS EM COTEJO COM A ABORDAGEM PRAGMATISTA

\begin{tabular}{|c|c|c|c|}
\hline $\begin{array}{l}\text { Elementos } \\
\text { de análise }\end{array}$ & $\begin{array}{l}\text { Abordagem racional } \\
\text { (Policy analysis) }\end{array}$ & $\begin{array}{l}\text { Abordagem argumentativa } \\
\text { (Policy studies) }\end{array}$ & $\begin{array}{l}\text { Abordagem } \\
\text { pragmatista }\end{array}$ \\
\hline $\begin{array}{l}\text { Compreensão de } \\
\text { política pública }\end{array}$ & $\begin{array}{l}\text { Ação governamental que } \\
\text { se expressa por meio dos re- } \\
\text { gistros oficiais da tomada de } \\
\text { decisão governamental tais } \\
\text { como leis, atos, regulamen- } \\
\text { tações e relatórios oficiais. }\end{array}$ & $\begin{array}{l}\text { Diferentes compreensões, } \\
\text { que incluem na análise as } \\
\text { ações, os atores, os espaços } \\
\text { e os argumentos, destacan- } \\
\text { do o processo e o caráter } \\
\text { político do fazer política. }\end{array}$ & $\begin{array}{l}\text { Ação pública, que vai além da } \\
\text { política pública, em resposta aos } \\
\text { problemas públicos. Trata-se de } \\
\text { um processo de experimentação, } \\
\text { de codefinição e codomínio das } \\
\text { situações problemáticas }\end{array}$ \\
\hline Espaço, lócus & Governo. & $\begin{array}{l}\text { Diferentes organizações } \\
\text { como não governamentais, } \\
\text { privadas, movimentos } \\
\text { sociais. }\end{array}$ & $\begin{array}{l}\text { Arenas públicas, articulações } \\
\text { negociadas, redes. }\end{array}$ \\
\hline $\begin{array}{l}\text { Dimensões de } \\
\text { análise }\end{array}$ & $\begin{array}{l}\text { O foco está nos resultados } \\
\text { e em sua relação com o } \\
\text { planejado/formulado, a } \\
\text { partir de uma análise neutra } \\
\text { e racional, sobretudo de } \\
\text { caráter quantitativo. }\end{array}$ & $\begin{array}{l}\text { Análise interpretativa, } \\
\text { considerando o processo e o } \\
\text { caráter político das políticas } \\
\text { públicas. }\end{array}$ & $\begin{array}{l}\text { Busca compreender as expe- } \\
\text { riências, a política enquanto elas } \\
\text { estão sendo feitas e acontecem } \\
\text { e os múltiplos enquadramentos, } \\
\text { engajamentos e visões dos atores }\end{array}$ \\
\hline Escalas de análise & Macroestratégica. & $\begin{array}{l}\text { Nos diferentes níveis, } \\
\text { estratégico, operacional e } \\
\text { básico. }\end{array}$ & $\begin{array}{l}\text { Em todo espectro da ação pública, } \\
\text { buscando ressaltar a interconexão } \\
\text { entre as escalas da realidade } \\
\text { (macro, meso e micro). }\end{array}$ \\
\hline $\begin{array}{l}\text { Compreensão do } \\
\text { problema público }\end{array}$ & $\begin{array}{l}\text { Algo dado a priori a partir } \\
\text { de análises oficiais e esta- } \\
\text { tísticas. }\end{array}$ & $\begin{array}{l}\text { Considera as múltiplas } \\
\text { dimensões dos problemas } \\
\text { públicos. }\end{array}$ & $\begin{array}{l}\text { Percepções compartilhadas } \\
\text { em processos de codefinição } \\
\text { e de codomínio de situações } \\
\text { percebidas como problemáticas } \\
\text { que provocam a mobilização de } \\
\text { diversos atores que passam a } \\
\text { agir coletivamente nas arenas } \\
\text { públicas. }\end{array}$ \\
\hline $\begin{array}{l}\text { Atores centrais e } \\
\text { protagonismo }\end{array}$ & $\begin{array}{l}\text { Atores governamentais, pro- } \\
\text { tagonismo dos especialistas. }\end{array}$ & $\begin{array}{l}\text { Diversidade de atores, pú- } \\
\text { blicos, privados e sociedade } \\
\text { civil. }\end{array}$ & $\begin{array}{l}\text { Multiplicidades de atores, interes- } \\
\text { ses, e formas de engajamento. }\end{array}$ \\
\hline $\begin{array}{l}\text { Relação entre os } \\
\text { atores }\end{array}$ & $\begin{array}{l}\text { Relação instrumental, } \\
\text { barganha. }\end{array}$ & $\begin{array}{l}\text { Diferentes tipos de relação e } \\
\text { discursos. }\end{array}$ & $\begin{array}{l}\text { Múltiplas formas de relações, } \\
\text { caracterizadas por processos de } \\
\text { cooperação e competição. }\end{array}$ \\
\hline $\begin{array}{l}\text { Lógica de Governan- } \\
\text { ça da PP }\end{array}$ & $\begin{array}{l}\text { Governança centrada } \\
\text { no governo, hierárquica } \\
\text { top-down. }\end{array}$ & Governança participativa . & $\begin{array}{l}\text { Governança colaborativa, experi- } \\
\text { mentalista. }\end{array}$ \\
\hline $\begin{array}{l}\text { Estudos e atores } \\
\text { centrais }\end{array}$ & $\begin{array}{l}\text { Lasswell (1950), Simon } \\
\text { (1957). }\end{array}$ & $\begin{array}{l}\text { Fisher e Forester (1996); } \\
\text { Hajer (1996); Radin (2000); } \\
\text { Stone (2002); Fischer, Miller } \\
\text { e Sidney (2007a; b). }\end{array}$ & $\begin{array}{l}\text { Dorf e Sabel (1998); } \\
\text { Zimmermann (2006); Shields } \\
\text { (2008); Sabel e Zeitlin (2015); } \\
\text { Ansell (2011; 2012); Berk (2012); } \\
\text { Lascoumes e Le Galès (2012). }\end{array}$ \\
\hline
\end{tabular}

Fonte: Elaborado pelos autores.

diferentes escalas influenciam umas às outras, como as ações e mudanças podem incidir no processo de governança do problema público e na própria política pública.

Dessa forma, para compreender e analisar as políticas públicas torna-se essencial olhar para as práticas, ou seja, acompanhar - in vivo - a experiência processual de múltiplos atores em diferentes escalas espaciais e temporais e em diferentes si- 
tuações vivenciadas e experimentadas (Gonsalves \& Andion, 2019). Nesse sentido, abordagens analíticas que priorizem a etnografia de arenas públicas (Magalhães, Andion \& Alperstedt, 2020; Andion, 2020) colocam-se como alternativas metodológicas interessantes para examinar as políticas públicas de outo modo.

Trata-se de considerar as políticas públicas enquanto elas se produzem, imersas em situações/experiências de resolução de problemas públicos. Para tanto, é importante capturar as diferentes cenas do "fazer política", nas quais diversos atores e actantes (Latour, 2012) com origens distintas têm poder de agência e fazem emergir múltiplas ações coletivas e formas de engajamento, eventos, memórias, representações e argumentos, instituições (normas, regras, convenções, procedimentos), processos, práticas e efeitos produzidos no tempo e no espaço. Considerar essa rede intricada de interações e as suas consequências nos parece essencial para compreender as dinâmicas de transformação da ação pública e seus efeitos reais na atualidade.

\section{Considerações finais}

Buscamos neste ensaio teórico evidenciar as contribuições da aplicação de uma leitura pragmatista, sobretudo aquela ancorada na teoria da democracia radical de John Dewey, para a análise da governança e das políticas públicas. Para finalizar, no Quadro 4, a seguir, apresentamos uma síntese das noções-chave e dos aspectos centrais das dinâmicas de investigação pública e de experimentação democrática exploradas no ensaio teórico aqui proposto.

Entretanto, é preciso lembrar, como salienta Dewey (1956: 560) em sua obra Lógica, teoria da investigação, que:

\footnotetext{
2. Para conhecer melhor as aplicações da etnografia de arenas públicas em estudos empíricos recomendamos a leitura das pesquisas realizadas no quadro do Núcleo de Inovações Sociais na Esfera Pública, no âmbito da Universidade do Estado de Santa Catarina. Em particular, recomenda-se as teses de Magalhães (2020) e Santo (2021).
}

\begin{abstract}
Os conceitos teóricos significativos começam a desempenhar seu papel unicamente quando o problema em questão é claro e definido; quer dizer a teoria por si só não pode dizer que relações podem ser estabelecidas e como pode ser entendido um determinado fenômeno (Dewey, 1956: 560).
\end{abstract}

Para transformar uma situação indeterminada em uma situação problemática não basta, segundo Dewey (1950), uma aproximação teórica, faz-se necessário adentrar o fenômeno e suas interações práticas². Esperamos assim que este ensaio seja inspirador para as pesquisas empíricas, ensejando novos enfoques analíticos e questões para o estudo da governança e a análise das políticas públicas, contribuindo para construção de novas trilhas e caminhos de fortalecimento das democracias, num mundo em que as mesmas estão cada vez mais em xeque em vários países e especialmente no Brasil. 


\section{QUADRO 4 \\ NOÇÕES-CHAVE DO PRAGMATISMO \\ PARA ANÁLISE DA GOVERNANÇA E DAS POLÍTICAS PÚBLICAS}

Estado democrático e ação pública: Existe uma diversidade de formas políticas e o arquétipo de Estado unificado ou do bom Estado é um mito. A formação do Estado é um processo experimental o qual está associado aos processos de investigação pública, por meio do engajamento dos públicos com os seus próprios problemas. É assim que o Estado democrático se forma e se transforma.

Investigação pública: Confrontadas com uma situação problemática é possível que as pessoas se inquietem, se interroguem, investiguem, experimentem, discutam, tentem definir o problema, determinar suas causas e seus efeitos e estabelecer as responsabilidades. Podem associar-se e organizar-se, tomar a palavra, testemunhar, avaliar, argumentar, criticar, deliberar, interpelar a opinião e os poderes públicos. Essa dinâmica coletiva pode fazer emergir ao mesmo tempo novas agendas de políticas públicas e novos públicos. Ela também é importante para garantir a publicização e o reconhecimento das questões públicas.

Público: Conjunto de pessoas, organizações e instituições indiretamente afetadas pela percepção compartilhada das consequências indesejadas da situação problemática e que podem ou não se mobilizar ou se sensibilizar para tentar resolvê-la.

Situação problemática: Situação que surge de um incômodo, de uma consequência percebida, que provoca perguntas e que, portanto, leva ao exame, ao debate e à investigação. Relaciona-se a uma experiência, por isso não é apenas sentida, mas também vivenciada.

Arena pública: Vai além dos dispositivos institucionais, técnicos ou jurídicos da ação pública e dos espaços de posições estruturadas de um campo político. É um lugar de combate, disputas, mas também de construção de acordos e realização de performances que promovem efeitos na ação pública.

Problematização: compreensão mais aprofundada e refletida de uma situação pública, suas causas, consequências e responsáveis etc.

Publicização: As consequências de uma situação problemática não concernem apenas àqueles indivíduos que a sofrem diretamente. Elas criam públicos que buscam agir sobre o problema e que também vão buscar novas composições e coalizões para o seu enfrentamento.

Experimentação democrática: Trata-se de um processo de resolução de problemas que alia inquirição (questionamento, construção de conhecimento e teste) com abordagens inclusivas e democráticas. Relaciona-se com a capacidade resolver os problemas comuns em resposta às crises externas, de forma colaborativa, gerando inteligência coletiva.

\section{Investigação pública - elementos centrais}

- Não é um processo natural; nem sempre um distúrbio ou situação problemática vai gerar uma investigação. É um processo dinâmico de resolução de problemas que envolve sentimento, observação, análise, hipótese e ação experimental.

- Os resultados da investigação são fundamentalmente provisórios: quaisquer resultados alcançados pela investigação (que podem ser codificados como "leis", "princípios" e assim por diante) devem ser entendidos como "confiáveis" ou "garantidos", mas nunca absolutamente "verdadeiros". Por isso a importância da criação do hábito/cultura da dúvida, do aprendizado evolutivo.

- É um processo que está sujeito a erros, a modificação, idas e vindas, por isso precisa ser autocorretivo. Diante de ambientes complexos e em constante mudança, as técnicas padrões de respostas e suposições específicas de qualquer investigação devem permanecer abertas para correção, modificação ou exclusão.

- A investigação nesse caso é sempre social: envolve colaboração e comunicação entre pessoas. A comunicação e a diversidade de atores e olhares sobre o problema em questão permite fomentar as possibilidades de pensamento reflexivo, aprendizado coletivo e do potencial de inovações.

- Apresenta ainda uma dimensão normativa de imputar responsabilidades, denunciar negligências, designar vítimas e culpados.

- A publicização é um elemento central para que o problema público possa chegar a diferentes níveis, esferas e agendas. É a capacidade de publicizar que possibilitará o problema público a ganhar destaque e ser foco da agenda política, podendo assim gerar mudanças no instituído.

- São em regra definidas em arenas públicas, em dinâmicas de colaboração e disputas, acomodamentos e competições, de negociações e arranjos, de protestos e consentimentos, de promessas e engajamentos, de contratos e convenções, de concessões e compromissos, de tensões e acordos mais ou menos simbolizados e ritualizados, formalizados e codificados. São portanto territorializadas e possuem características particulares, repertórios de ação e uma cultura política que influencia em suas dinâmicas.

- Se estabelecem no decorrer de longas trajetórias, com momentos de descontinuidade, de calmaria, de constante ação em que se configuram as situações de prova, isso porque os problemas públicos são frutos de longas trajetórias não lineares, da cristalização das situações de prova.

- Permitem gerar conhecimentos e experiências, dispositivos e uma capacidade nos atores de enquadramento do problema, possibilitando a construção de argumentos e críticas, bem como a escolha de determinados cursos de ação incidindo nas trajetórias dos problemas públicos. 
- A experimentação democrática não assume que haverá transformações, mas busca fomentar as condições para que possa ocorrer. Apesar de o foco estar nas instituições, há uma diversidade de formas de experimentação que ocorrem fora dos ambientes institucionais e que precisam ser consideradas na análise.

- As experimentações democráticas podem promover o potencial inovador do qual os processos de democratização, transformação e inovação social dependem. Isso porque, ao possibilitar os atores experimentarem soluções alternativas para os problemas complexos, promovem a pluralidade e a inclusão podendo, gerar aprendizado reflexivo e coletivo em resposta aos problemas públicos.

- Desse modo pode-se institucionalizar o exercício da dúvida voltado para o questionamento permanente das rotinas na administração pública. Na experimentação os testes têm, em primeiro lugar, validade local porque estão enraizados em problemas cuja forma não é universal, mas dependem de variáveis contextuais. Por isso, a importância de se atentar para os níveis mais amplos e a troca de conhecimentos com outras realidades. Esse processo define procedimentos padrão para permitir a comparação de dados produzidos, de acordo com procedimentos homogêneos, preservando a autonomia local e, ao mesmo tempo, possibilitando a aprendizagem coletiva.

- Por outro lado, por meio da descentralização, aumenta a chance de que aqueles que são afetados por um problema possam participar da busca de soluções. Isso porque se amplia a participação desde a percepção inicial de um problema até o momento final da tomada de decisão ao longo do processo de experimentação, valorizando os recursos epistêmicos dos atores locais e impulsionando ativos, ao invés do envolvimento passivo em práticas e instituições sociais.

- A experimentação democrática também não é algo natural e exige fomento e fortalecimento das experiências, e por isso a importância do fortalecimento das redes e da inclusão de diferentes atores promovendo maiores níveis de reflexividade e colaboração.

- É um processo que exige a inclusão concreta dos atores, baseado numa perspectiva da governança colaborativa, de inclusão em todas as etapas, uma vez que os atores possuem diferentes enquadramentos da situação, e isso permite gerar legitimidade.

Fonte : Elaborado pelos autores, com base nas referências citadas.

\section{Referências}

AMARAL, Maria N. Dewey: filosofia e experiência democrática. São Paulo: Perspectiva, 2007.

ANDION, Carolina. Atuação da sociedade civil no enfrentamento dos efeitos da Covid-19 no Brasil. Revista de Administração Pública, v. 54, n. 4, p. 936-951, 2020. Disponível em: <https://bibliotecadigital.fgv.br/ojs/index.php/rap/article/ view/81891>.

Por uma nova interpretação das mudanças de paradigma na administração pública. Cadernos Ebape, v. 10, n. 1, p. 1-19, 2012.

ANSELL, Chris. What is democratic experiment? Contemporary Pragmatism, v. 9, n. 2, p. 159-180, 2012.

Pragmatist democracy: evolutionary learning as public philosophy. Oxford, UK: Oxford Scholarship Online, 2011.

ANSELL, Chris; S $\varnothing$ RENSEN, Eva; TORFING, Jacob. The COVID-19 pandemic as a game changer for public administration and leadership? The need for robust governance responses to turbulent problems. Public Management Review, v. 23, n. 1, p. 1-12, Set. 2020. 
BAUMAN, Zygmunt. Em busca da política. Rio de Janeiro: Zahar, 2000.

BERK, Gerald, On Christopher K. Ansell pragmatist democracy: evolutionary learning as public philosophy. Socio-Economic Review, v. 10, n. 3, Jul. 2012. Disponível em: <https://doi.org/10.1093/ser/mwr040>.

BOHMAN, James. Democratic experimentalism: from self-legislation to self-determination. Contemporary Pragmatism, v. 9, n. 2, p. 273-285, Dez. 2012.

Réaliser la démocratie délibérative comme mode d'enquête: le pragmatisme, les faits sociaux et la théorie normative. Tracés - Revue de Sciences Humaines, n. 883, 2008.

Realizing deliberative democracy as a model of inquiry: pragmatism, social facts and normative theory. Journal of Speculative Philosophy, v. 18, n. 1, p. 3-4, 2004.

BOULLOSA, Rosana F. Mirando ao revés nas políticas públicas: notas sobre um percurso de pesquisa. Pensamento e Realidade, v. 8, n. 3, 2013.

BOVET, Alain; TERZI, Cédric. La composante narrative des controverses politiques et médiatiques: pour une analyse praxéologique des actions et des mobilisations collectives. Réseaux, n. 132, p. 111-132, 2012.

BRIGGS, Xavier. Democracy as problem solving: civic capacity in communities across the globe. Cambridge, MA: MIT Press, 2008.

CABRAL, Caio. As bases naturalísticas da teoria da investigação de John Dewey. Dissertação (Mestrado em Filosofia) - Faculdade de Filosofia, Letras e Ciências Humanas da Universidade de São Paulo, São Paulo, SP, 2014.

CASTELLS, Manuel. Ruptura: a crise da democracia liberal. São Paulo: Zahar, 2018.

CARVALHO, Luís Miguel. As políticas públicas de educação sob o prisma da ação pública: esboço de uma perspectiva de análise e inventário de estudos. Currículo sem Fronteiras, v. 15, n. 2, p. 314-333, Maio-Ago. 2015

CEFAï, Daniel. Públicos, problemas públicos, arenas públicas: o que nos ensina o pragmatismo. Novos Estudos Cebrap, v. 36, n. 1, p. 187-213, Mar. 2017.

L'enquête ethnographique comme écriture. l'écriture ethnographique comme enquête. In: MELLITI, Imed (Éd.). La fabrique du sens: écrire en sciences sociales. Marseille, FR: Riveneuve éditions 2016. 
. “¿Qué es una arena pública? Algunas pautas para un acercamiento pragmático." In. CEFAï, Daniel; JOSEPH, Isaac (Orgs.). La herencia del pragmatismo. Conflictos de urbanidad y pruebas de civismo, p. 51-81. La Tour d'Aigues, FR: Éditions de l'Aube, 2012.

. Diez propuestas para el estudio de las movilizaciones colectivas. De la experiencia al compromiso. Revista de Sociología, n. 26, p. 137-166, Santiago de Chile, 2011.

Como nos mobilizamos? A contribuição de uma abordagem pragmatista para a sociologia da ação coletiva. Dilemas. Revista de Estudos de Conflitos e Controle Social, v. 2, n. 4, p. 11-48, 2009.

Qu'est-ce qu'une arène publique? Quelques pistes pour une approche pragmatiste. In: CEFAÏ, Daniel; JOSEPH, Isaac (Orgs.). L'héritage du pragmatisme. Conflits d'urbanité et épreuves de civisme. La Tour d'Aigues, FR: Éditions de I'Aube, 2002.

CEFAÏ, Daniel; TERZI, Cedric. L'expérience de problèmes publics. Paris: Perspectives Pragmatistes, 2012.

CHATEAURAYNAUD, Francis. Argumenter dans un champ de forces: essai de balistique sociologique. Paris: Éditions Pétra, 2011.

COMMAILLE, Jacques; JOBERT, Bruno. Les métamorphoses de la régulation politique. Droit et Société, v. 24, Paris, 1999.

CONSIDINE, Mark. Making public policy: institutions, actors, strategies. Cambridge, UK: Polity, 2005.

DALLA CORTE, Tiago; DALLA CORTE, Thaís. A democracia no século XXI: crise, conceito e qualidade. Passagens: Revista Internacional de História Política e Cultura Jurídica, v. 10, n. 2, 2018.

DENHARDT, Janet V.; DENHARDT, Robert. The new public service: steering, not serving. New York: Sharpe, 2003.

DEWEY, Jonh. Lógica: teoría de la investigación. New York: Holt, 1956.

The public and its problems. Chicago, MI: Swallow Press, 1927.

DORF, Michael C.; SABEL, Charles F. A constitution of democratic experimentalism. Columbia Law Review, v. 98, n. 2, 1998. 
DYE, Thomas R. Policy analysis: what governments do, why they do it, and what difference it makes. Tuscaloosa, AL: University of Alabama Press, 1976.

FARAH, Marta F. Análise de políticas públicas no Brasil: de uma prática não nomeada à institucionalização do "campo de públicas". Rev. Adm. Pública, v. 50, n. 6, 2016.

FERREIRA, Maria Cristina. The notion of experience in John Dewey, progressive education and science curriculum. Anais VIII Enpec, Campinas, SP, 2011.

FESTENSTEIN, Matthew. Inquiry as critique: on the legacy of deweyan pragmatism for political theory. Political Studies, v. 49, n. 4, 2001.

FISCHER, Frank; FORESTER, John. The argumentative turn in policy analysis and planning. Durham, NC: Duke University Press Books, 1996.

FISCHER, Frank; MILLER, Gerald; SIDNEY, Mara. Handbook of public policy analysis. Abingdon, UK: Taylor \& Francis, 2007a.

. Handbook of public policy analysis: theory, politics and methods. London; New York: Routledge, 2007b.

FREGA, Roberto. Pragmatism and the wide view of democracy. Gewerbestrasse, $\mathrm{CH}$ : Palgrave Macmillan, 2019.

FUKUYAMA, Francis. Is democracy in decline? Journal of Democracy, v. 26, n. 1, 2015.

FUNG, Archon. Deliberative democracy and international labor standards. Governance, v. 16, n. 1, 2002.

FUNG, Archon; WRIGHT, Erik Olin. Deepening democracy: institutional innovations in empowered participatory governance. London: Verso, 2003.

GONSALVES, Agatha K.; ANDION, Carolina. Ação pública e inovação social: uma análise do sistema de garantia de direitos da criança e do adolescente de florianópolis. Revista O\&S, v. 2, n. 3, 2019.

GUERREIRO RAMOS, Alberto. A modernização em nova perspectiva: em busca do modelo da possibilidade. In: HEIDEMANN, Francisco G.; SALM, José Francisco (Orgs.). Políticas públicas e desenvolvimento: bases epistemológicas e modelos de análise. Brasília: Editora UnB, 2009.

HABERMAS, Jürgen. Mudança estrutural na esfera pública. Rio de Janeiro: Tempo Brasileiro, 1984. 
HAJER, Maarten. Coalitions, practices, and meaning in environmental politics: from acid rain to BSE. In: Howarth et al. (Eds.). Discourse theory in european politics, 1996.

HOWLETT, Michael; RAMESH, M.; PERL, Anthony. Política pública: seus ciclos e subsistemas. Uma abordagem integral. Rio de Janeiro: Elsevier, 2013.

IAZZETTA, Osvaldo. Democracia, calidad de la democracia y democratización. Revista Debates, v. 7, n. 1, p. 139-150, Jan.-Abr. 2013.

JOSEPH, Isaac. L'athlète moral et l'enquêteur modeste. Parcours du pagmatisme. In: KARSENTI, Bruno; QUÉRÉ, Louis (Eds). La croyance et l'enquête. Aux sources du pragmatisme, p.19-52. "Raisons Pratiques", v. 15. Paris: Éditions Ehess, 2004.

KARSENTI, Bruno; QUÉRÉ, Louis (Eds.). La croyance et l'enquête: aux sources du pragmatisme. "Raisons Pratiques", v. 15. Paris: Éditions de l’EHESS, 2004.

KISSLER, Leo; HEIDEMANN, Francisco G. Governança pública: novo modelo regulatório para as relações entre Estado, mercado e sociedade? Revista de Administração Pública, v. 40, n. 3, 2006.

LASCOUMES, Pierre; LE GALÈS, Patrick. Sociologia da ação pública. Maceió: Editora da Ufal, 2012.

Sociologie de l'action publique. Paris: Armand Colin, 2007.

LASWELL, Harold D. Politics: who gets what, when, how. Cleveland, $\mathrm{OH}$ : Meridian Books, 1936-1958.

. The decision process: seven categories of functional analysis. College Park, MD: The Oxford Handbook of Classics in Public Policy and Administration, 1956.

LATOUR, B. Reagregando o social: uma introdução à teoria do ator-rede. Salvador: Editora UFBA, 2012.

LAVALLE, Adrian Gurza; SZWAKO, José. Sociedade civil, Estado e autonomia: argumentos, contra-argumentos e avanços no debate. Opinião Pública, v. 21, n. 1, p. 157-187, Abr. 2015.

LEFORT, Claude. The political forms of modern society: bureaucracy, democracy, totalitarianism. Cambridge, MA: MIT Press, 1986.

LEVISTIKY, Steven; WAY, Lucan Ahmad. The myth of democratic recession. Journal of 
Democracy, v. 26, n. 1, 2015.

LEVISTIKY, Steven; ZIBLATT, Daniel. How democracies dies. New York: Penguin Random House, 2019.

LINDBLOM, Charles. The science of "muddling through". Public Administration Review, v. 19, n. 2, 1959.

LIPSKY, Michael. Street level bureaucracy: dilemmas of the individual in public services. New York: Russell Sage Foundation, 1980.

LYNN, Lawrence E. Design public policy: a casebook on the role of policy analysis. Santa Monica, CA: Goodyear, 1980.

MAGALHÃES, T. Garantir direitos não é brincadeira! Investigação, experimentação e inovação social na política pública de proteção integral de crianças e adolescentes em Florianópolis. Tese (Doutorado) - Universidade do Estado de Santa Catarina (Udesc), Centro de Ciências da Administração e Socioeconômicas (ESAG), Programa de Pós-Graduação em Administração, Florianópolis, 2020.

MAGALHÃES, Thiago G.; ANDION, Carolina; ALPERSTEDT, Graziela D. Social innovation living labs and public action: an analytical framework and a methodological route based in pragmatism. Cadernos Ebape, v. 18, número especial, p. 680-696, Nov. 2020

MARCH, James G. Exploration and exploitation in organizational learning. Organization Science, v. 2, n. 1, p. 71-87, 1991.

MARQUES, Eduardo; FARIA, Carlos Aurélio. A política pública como campo multidisciplinar. São Paulo; Rio de Janeiro: Editora Unesp; Editora Fiocruz, 2013.

MONEDERO, Juan Carlos. 15M and indignant democracy: legitimation problems within neoliberal capitalism. In: PEREIRA-ZAZO, Óscar; TORRES, Steven (Eds.). Spain after the Indignados/15M Movement. London: Springer International Publishing; Palgrave Macmillan, 2019.

MOTTA, Paulo Roberto M. O estado da arte da gestão pública. Rev. Adm. Empresa, v. 53, n. 1, 2013.

MULLER, Pierre. Les entrepreneurs ruraux: agriculteurs, artisans, commerçants, élus locaux. Grenoble, FR: Université des Sciences Sociales de Grenoble, 1989.

OFFE, Claus. New social movements: challenging the boundaries of institutional politics. Social Research, v. 52, 1996. 
PAGE, Edward C. How policy is really made. London: Public Management and Policy Association, 2006.

POLLITT, Christopher; BOUCKAER, Geert. Public management reform: a comparative analysis. Long Range Planning, v. 33, n. 6, 2002.

QUÉRÉ, Louis; TERZI, Cedric. Pour une sociologie pragmatiste de l'expérience publique. Quelques apports mutuels de la philosophie pragmatiste et de l'ethnométhodologie. Sociologies [en ligne], "Dossiers. Pragmatisme et sciences sociales: explorations, enquêtes, experimentations", 2015. Disponível em: < https://doi. org/10.4000/sociologies.4949>.

RADIN, Beryl A. Beyond Machiavelli: policy analysis comes of age. Washington, DC: Georgetown University Press, 2000.

ROSE, Richard. Getting things done with social capital. New Russia Barometer VII Studies in Public Policy, n. 303, 1994.

SABEL, Charles. Dewey, democracy and democratic experimentalism. Contemporary Pragmatism, v. 9, n. 2, 2012.

SABEL, C.; ZEITLIN, J. Experimentalist governance. In: LEVI-FAUR, D.. (Ed.). The Oxford Handbook of Governance. Oxford, UK: Oxford University Press, 2015.

SANTO, A. L. E. No rural tem inovação social! Um estudo em dois assentamentos rurais na zona fronteiriça Brasil-Bolívia. Tese (Doutorado) - Universidade do Estado de Santa Catarina (Udesc), Centro de Ciências da Administração e Socioeconômicas (Esag), Programa de Pós-Graduação em Administração, Florianópolis, 2021.

SANTOS, Boaventura de Souza. Public sphere and epistemologies of the South. Africa Development, v. 37, n. 1, 2012.

SANTOS, Boaventura de Souza; AVRITZER, Leonardo. Para ampliar o cânone democrático." In: SANTOS, Boaventura de Souza (Org.). Democratizar a democracia. Rio de Janeiro: Civilização Brasileira, 2003.

SIMON, Herbert A. Administrative behavior: a study of decision-making processes. In: Administrative organization. 2. ed., New York: Macmillan, 1957.

SHIELDS, Patricia M. The community of inquiry: insights for public administration from Jane Addams, John Dewey and Charles S. Pierce. Public Administration Theory Network, 2008. Disponível em: < https://digital.library.txstate.edu/bitstream/handle/10877/3979/fulltext.pdf?sequence=1\&isAllowed=y>. 
SOUZA, Celina. Estado da arte da pesquisa em políticas públicas. In.: HOCHMAN, Gilberto; ARRETCHE, Marta; MARQUES, Eduardo (Orgs.). Políticas públicas no Brasil, p. 65-86. Rio de Janeiro: Editora Fiocruz, 2007.

STAVO-DEBAUGE, Joan. Le loup dans la bergerie: le fondamentalisme chrétien à l'assaut de l'espace public. Genève, CH: Labor \& Fides, 2012.

STAVO-DEBAUGE, Joan; TROM Danny. Le pragmatisme et son public à l'épreuve du terrain. Penser avec Dewey contre Dewey. in KARSENTI, Bruno; QUÉRÉ, Louis (Dirs.). La croyance et l'enquête: aux sources du pragmatisme. Paris: Éditions de l'Ehess, 2004.

STONE, Deborah. Policy paradox: the art of political decision making. New York: W.W. Norton \& Company, 2002.

TERZI, Cedric. The publicization of public space. Environment and planning A: Economy and Space, v. 49, n. 3, 2015.

THOENIG, Jean-Claude. L'ère des technocrates: le cas des ponts et chaussées. Paris: Éditions l'Harmattan, 1973.

THE ECONOMIST INTELLIGENCE UNIT (EIU). Democracy Index 2020: In sickness and in health? 2020.

ZASK, Joëlle. L'enquête sociale comme inter-objectivation. Paris: Éditions de l'Ehess, 2004.

ZELIZER, Viviana A. A negociação da intimidade. Petrópolis, RJ: Vozes, 2011 [2005].

ZIMMERMANN, Bénédicte. Pragmatism and the capability approach: challenges in social theory and empirical research. European Journal of Social Theory, v. 9, n. 4, 2006. 